\title{
EFFECT OF GRAVEL DUST AND LIMESTONE DUST ON GEOTECHNICAL PROPERTIES OF CLAYEY SOIL
}

\author{
Hussein Jalal Aswad Hassan", ShaAfan AbDUllah TAHeR ${ }^{2, * *}$ and Sheyan Alyousify ${ }^{* *}$ \\ "Dep. of Civil Engineering, College of Engineering, University of Duhok, Kurdistan region-Iraq \\ ** Technical College of Engineering, Duhok Polytechnic University, Kurdistan region-Iraq
}

(Accepted for Publication: December 8, 2020)

\begin{abstract}
Gravel dust and limestone dust are types of solid waste materials that are obtained from the crusher plant. These materials are dumped-off in high amount causing a negative impact on the environment and creating serious hazards on health. As the construction activities are increased in developing countries, the demand of crushed gravel and crushed limestone for roads, airfields, railway ballast, buildings and concrete work are increased. This study attempted to investigate the effect of gravel dust and limestone dust on geotechnical properties of clayey soil. Testing program including Atterberg limits, compaction, CBR and free swell tests, were performed on clay with the dust at varying amounts $(10,20,30$ and $40 \%)$. The results showed that the Atterberg limits of clay decrease in proportion to increases in the amount of dust. The increase in gravel dust contents decreased the compaction characteristics of clay. However, the MDD increased and OMC decreased with increase in limestone dust contents. A series of soaked CBR tests were conducted on the clay-dust mixtures of gravel dust and limestone dust. The dust was mixed with the clay of different weight percentages. The results showed a general increase in the CBR value of clay with the addition of dust. The CBR value increased gradually with the gravel dust content. The maximum CBR was obtained at optimum limestone dust content, approximately $20 \%$. Swelling percentages decreased gradually with the dust content. The tests results revealed that it is possible to use gravel dust and limestone dust for improving the properties of clayey soil.
\end{abstract}

KEYWORDS: Clay-dust; Gravel dust; Limestone dust; CBR; Atterberg limits; Compaction

\section{INTRODUCTION}

$\mathbf{I}$ ncrease in population growth and construction activities resulted in high demand of crushed gravel and limestone for roads, railway ballast, buildings and concrete work globally. For crushing gravel and limestone, a large number of crusher units are installed. The dust is produced by blasting and crushing of gravel and limestone in mechanical crushers. A large amount of these waste materials are not reutilized but are rather disposed of somewhere in the limited number of available spaces of disposal sites as well as leads to the health and environment problems. Therefore, recycling of these materials is becoming high concern by many countries in the world. Many researchers are trying to find alternative methods of recycling these materials and eliminating their hazardous impact. One of these methods is using these materials as soil stabilizer. The problematic issue of soils such as soft and expansive clays, are to be treated for improving their bearing capacity, swelling and settlement behaviour. The 
construction of structures foundation, highways, roads and runways by these soils affect its stability, due to its shrinkage and swelling excessively. Gravel dust and limestone dust are two cheaper waste materials that have effective properties that can be used as stabilization materials in the expansive clay.

Various studies have shown that the utilization of dust has a significant effect in the field of soil stabilization. They have used dust materials as admixtures and showed good results in soil stabilization. The use of dust in road constructions leads to improve strength, workability and volume stability. Crusher dust has great advantageous in the stabilization of soil beds, and subgrade layer in the flexible pavements. study the effect of these waste materials on the mechanical and physical properties of soil. Tiwari et al. (2016) used stone dust and polypropylene fibres for enhancing the properties of black cotton soil. Their results showed that the strength of black cotton soil significantly increased after the addition of stone dust and polypropylene fibre as stabilized material. Pastor et al. (2019) carried out different standardized tests to evaluate the effect of limestone power on properties of clayey soil. Also, they conducted X-Ray diffraction and $\mathrm{X}$-Ray Fluorescence to characterize the native soil and additives. Generally, their results showed that the addition of limestone powder improves the geotechnical properties of soil like increase in soil strength and a decrease in its deformability. Memon et al. (2015) studied the effect of limestone dust as a stabilizer for improving the swelling properties of expansive soils and their study revealed when soil mixed with $20 \%$ limestone dust, free swelling ratio reduced by $41.5 \%$ and caused the soil to be
There are various researchers attempted to

non-swelling soil. Dixit and Patil (2016) investigated the utilization of stone dust for enhancing the properties of soil. They carried out standard geotechnical tests such as Atterberg limits, Compaction and California bearing ratio (CBR). The study showed an improvement in these properties after the addition of stone dust at different dosage rates. Malik and Priyadarshee (2018) conducted compaction and swell tests to evaluate the effect of stone dust, husk ash and fly ash on clayey soil. Their study showed an improvement in the compaction and swelling behaviour of soil after the addition of these additives. Sabat and Muni (2015) reported that addition limestone dust increased unconfined compression strength and CBR value and improve Atterberg limits of clayey soil. Agrawal and Gupta (2011) investigated the effect of addition randomly distributed stone dust on compaction, specific gravity and CBR of soil. The percentage of rates of stone dust added soil were $(10 \%, 20 \%, 30 \%, 40 \%$ and $50 \%)$. The study concluded that mixing soil with stone dust has a significant effect on soil properties. Bshara et al. (2014) investigated the usefulness of weak soil to be used for sub-grade material after the addition of stone dust. The study concluded that soil stone dust mixture improved the CBR and maximum dry density (MDD) of weak soil. Also, the study indicated that decrease by adding stone dust, the liquid limit, plastic limit, plasticity index and optimum moisture content (OMC) decreased. Thus, these results proved the usefulness of soil as subgrade soil.

In this research, the effect of gravel dust and limestone dust as soil stabilizers on the performance of clayey soil is investigated. The study examines the effect of these two additives at various dust contents on Atterberg limits, compaction properties, CBR and swelling behaviour of clayey soil.

$$
\text { hussein.hassan@uod.ac, en.shevan@yahoo.com, sheyan.khaled@dpu.edu.krd }
$$

${ }^{2}$ Corresponding author: Directorate of Roads and Bridges in Duhok, Kurdistan Region, Iraq 


\subsection{Soil}

\section{MATERIALS}

The clay sample was obtained from the project (construction of the road between Girsheen and Suheila intersection), Zakho district, Duhok city, Iraq. The clay was collected from a depth of $2 \mathrm{~m}$ below the ground level because the fairly homogeneous sample can be available at depth (Figure 1). The clay properties are shown in Table 1.

Table (1): Properties of used clay soil

\begin{tabular}{ccc}
\hline Property & Value & Standard \\
\hline AASHTO Soil Classification & A-7-6 & AASHTO M 145 \\
\hline USCS Classification & $\mathrm{CH}$ & ASTM D2487 \\
\hline Liquid Limit (LL) (\%) & 51 & ASTM D4318 - 10 \\
\hline Plastic Limit (PL) (\%) & 26 & ASTM D4318 - 10 \\
\hline Plasticity Index (PI) (\%) & 25 & ASTM D4318 - 10 \\
\hline Shrinkage Limit (SL) (\%) & 16 & ASTM D4318 - 10 \\
\hline Swelling (\%) & 8.47 & ASTM D1883 - 07 \\
\hline Maximum Dry Density (MDD) (g/cm $\left.{ }^{3}\right)$ & 1.800 & ASTM D1557 - 09 \\
\hline Optimum Moisture Content (OMC) (\%) & 15.9 & ASTM D1557 - 09 \\
\hline CBR Soaked (\%) & 3.2 & ASTM D1883 - 07 \\
\hline Total Soluble Salts (\%) & 1.593 & BS 1377 \\
\hline Organic Materials (\%) & 1.646 & BS 1377 \\
\hline
\end{tabular}

\subsection{Dust}

Two types of dust have been used in this study were: gravel dust and limestone dust, as shown in Figure 1. The gravel dust was collected from a crusher plant situated at Kully village in Duhok city. The sources of gravel dust was stones collected from Khabor River for crushed gravel layer used in the project (construction of the road between Girsheen and Suheila intersection). Limestone dust was collected from crusher plant situated at Bekher Mountain in Zakho district, Duhok city, Iraq. The properties of gravel dust and limestone dust are shown in Table 2 .

Table (2): Properties of gravel dust and limestone dust

\begin{tabular}{cccc}
\hline Property & $\begin{array}{c}\text { Gravel } \\
\text { Dust }\end{array}$ & $\begin{array}{c}\text { Limestone } \\
\text { Dust }\end{array}$ & Standard \\
\hline Percentage Passing by Weight, Sieve No.50 $(0.3 \mathrm{~mm})$ & 100 & 99 & ASTM C136 \\
\hline Percentage Passing by Weight, Sieve No.200 $(0.075 \mathrm{~mm})$ & 73 & 79 & ASTM C136 \\
\hline LL, PL, PI and SL $(\%)$ & NP & NP & ASTM D4318 - 10 \\
\hline MDD $\left(\mathrm{g} / \mathrm{cm}^{3}\right)$ & 1.675 & 1.847 & ASTM D1557 - 09 \\
\hline OMC $(\%)$ & 17.3 & 12.4 & ASTM D1557 - 09 \\
\hline CBR Soaked $(\%)$ & 37 & 11.6 & ASTM D1883 - 07 \\
\hline CaCO3 $(\%)$ & 73 & 98 & ASTM D4373 \\
\hline
\end{tabular}


Despite that both applied dust have $\mathrm{CaCO} 3$, it is anticipated that gravel dust will behave as a replacement material of clay content in the soil. However, with the addition of limestone dust to soil mixture, it will result in chemical reactions between the elements of limestone dust and soil (Ahmed et al., 2020).

Limestone dust is obtained from crushing limestone. Limestone is a type of sedimentary rock consisted high level of calcium carbonate (CaCO3). By subjecting limestone to extreme heating will produce quick lime (calcium oxide)
$(\mathrm{CaO})$. With addition of water to quick lime will produce hydrated lime (calcium hydroxide) $(\mathrm{Ca}(\mathrm{OH}) 2)$. To compare with limestone, quicklime and hydrated Lime have a higher calcium carbonate equivalent percentage (CCE) (i.e. more than 100\%). According to Pete Lien and Sons (2015), the CCE of these three materials are as follow:

Limestone (CaCO3): 80-100\%, Hydrated Lime $(\mathrm{Ca}(\mathrm{OH}) 2): 120-135 \%$ and Quicklime $(\mathrm{CaO}): 150-175 \%$.

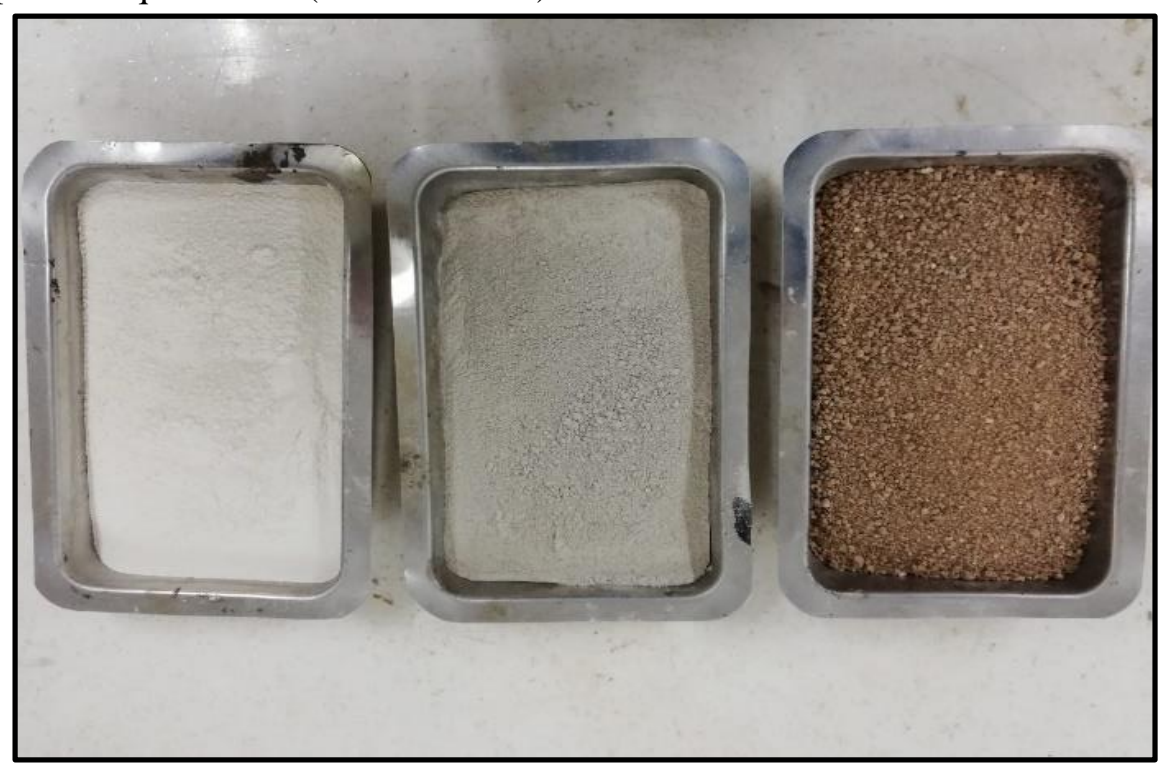

Fig. (1): Limestone dust (left), gravel dust (middle) and clayey soil (right)

\section{METHODOLOGY}

Atterberg limits tests were conducted in accordance with ASTM D4318 - 10. The tests were undertaken to investigate the effects of gravel dust and limestone dust on the liquid limit, plastic limit, plasticity index and shrinkage limit of soil. Samples were prepared by mixing soil with different dosages of dust $(10 \%, 20 \%, 30 \%$ and $40 \%$ ) of soil weight. The liquid limit test was carried out by determining the number of blows from the cup being dropped $1 \mathrm{~cm}$ a standard Casagrande device. The liquid limit is the water content determined at the 25 blows. The plastic limit is the water content which is determined by rolling the soil sample into $3 \mathrm{~mm}$ threads without crumbling. The shrinkage limit with the moisture content of liquid limit determined for each sample after 24 hours at $25^{\circ} \mathrm{C}$.

The modified compaction test was performed according to ASTM D1557 - 09. The test was conducted to find the effect of gravel dust and limestone dust on the maximum dry density (MDD) and optimum moisture content (OMC). The soil mixed with gravel dust and limestone dust at ratios 0:100, 10:90, 20:80, 30:70 and 40:60 by weight. The sample was compacted in a $1000 \mathrm{~cm}^{3}$ compaction mold in five equal thickness layers, with ramming at 25 blows per layer using $4.54 \mathrm{Kg} \mathrm{lb}$ hammer falling a distance of $45.72 \mathrm{~cm}$.

hussein.hassan@uod.ac, en.shevan@yahoo.com,_sheyan.khaled@dpu.edu.krd

${ }^{2}$ Corresponding author: Directorate of Roads and Bridges in Duhok, Kurdistan Region, Iraq 
The CBR test in accordance with ASTM D1883 - 07, was conducted on the soil mixed with four different dosages of $10 \%, 20 \%, 30 \%$ and $40 \%$ dust by weight for both types of gravel dust and limestone dust. The MDD and OMC for the soil-dust mixture were determined from the modified proctor test. The CBR apparatus consisted of cylindrical mold $150 \mathrm{~mm}$ in internal diameter and height $175 \mathrm{~mm}$ with a base plate and a collar, a loading frame with a cylindrical plunger of $50 \mathrm{~mm}$ diameter. The load is applied at a rate of $1.25 \mathrm{~mm} / \mathrm{min}$. Three samples 12,30 and 56 blows for each concentration were soaked in water for 96 hours under a surcharge of $5 \mathrm{~kg}$. The value of CBR is recorded for penetrations at $2.5 \mathrm{~mm}$ and $5.0 \mathrm{~mm}$ for 12,30 and 56 blows. The curve Y-axis CBR and X-axis dry density were plotted and final CBR value found at $0.95 \%$ of MDD. Swelling for each sample was recorded in the final reading of the dial gauge at the end of the soaking period.

\section{RESULTS AND DISCUSSION}

\subsection{Atterberg Limits}

The liquid limit (LL), plastic limit (PL), and plasticity index (PI) for native soil were $51 \%$, $26 \%$, and $25 \%$, respectively. Generally, as the percent of dust increased, the Atterberg limits decreased. The effect of limestone dust and gravel dust on Atterberg limits of soil can be seen in figure 2 and figure 3 respectively.

In general, increasing limestone dust content leads to reducing LL, PL and PI. Figure 2 demonstrates that for limestone dust contents equal to $10 \%, 20 \%, 30 \%$ and $40 \%$; LL is decreased by $6 \%, 10 \%, 12$ and 17\%; PL is reduced by $4 \%, 5 \%, 6$ and $8 \%$; and PI is decreased by 3\%, 5\%, 6 and 9\%; respectively. Similar results were found by various researchers like Ahmed et al. (2020), Bshara et al. (2014) and Sabat (2012).

Brooks et al. (2011) stated that as the limestone dust added to the soil, the calcium cation in the dust will take place of soil cations until the soil full of calcium cations. This result in a significant decrease in the thickness of diffuse double layer and which in turn result in a decrease in LL and PL. The soil limestone dust mixture will result in a pozzolanic reaction which in turn create cementitious compounds and fill the soil voids and cause a reduction in PI of soil (Okagbue, 2007; Brooks et al., 2011). According to Ahmed et al. (2020), adding limestone powder will improve both workability and consistency of soil. Thompson (1967) stated that as PI decrease, the workability of soil mixture increase. Negi et al. (2013) concluded that the addition of lime to the soil will flocculate and agglomerate the soil of soil particles and hence will improve the consistency of soil.

For the addition of gravel dust to the soil, increasing gravel stone dust content leads also to reducing LL and PI with slightly increasing PL. Figure 3 shows that for gravel dust contents equal $10 \%, 20 \%, 30 \%$ and $40 \%$; LL is decreased by $4 \%, 7 \%, 10 \%$ and $14 \%$; and PI is decreased by $6 \%, 8 \%, 12 \%$ and $16 \%$; respectively. The PL increased up to $10 \%$ content of gravel dust and then remained almost constant up to $40 \%$. These results were similar to the results of Agrawal and Gupta (2011), Satyanarayana et al. (2013) and Sivrikaya et al. (2014).

Dixit and Patil (2016) found that reduction of LL is due to the addition of stone dust which is considered as non-plastic material. Adding gravel dust will decrease both the ability of binding and capacity of retaining the moisture of the soil-gravel dust mixture (Kashoborozi et al., 2017).

Generally, the PI of soil decreased with the addition of both limestone dust and gravel dust. This due to the reduction of clay fines with addition bots dust as they are non-plastic materials. It is worth to mention that the decrease in PI is considered an improvement in the soil properties as it decreases the affinity of soil to water (Tugume et al., 2018). The results 
of this study showed that gravel dust is more limestone dust. effective in term of reducing PI to compare with

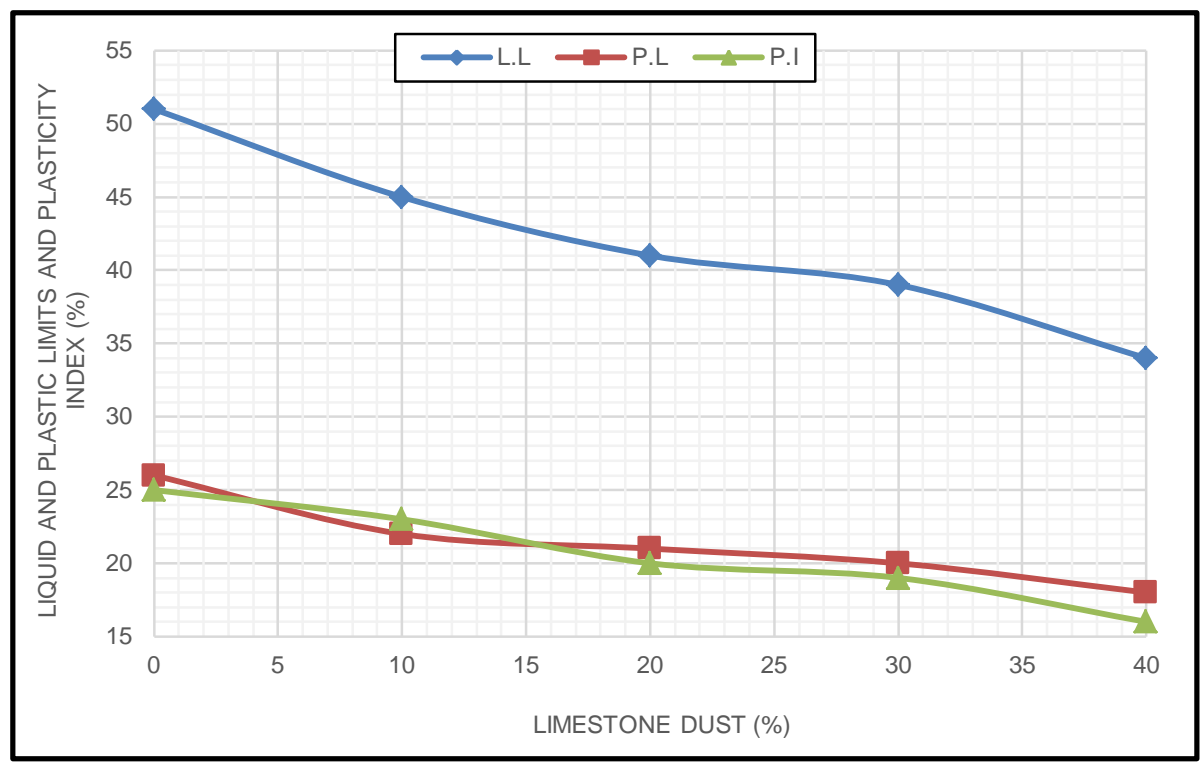

Fig. (2): Variation of liquid limit, plastic limit and plasticity index for clay as limestone dust increases

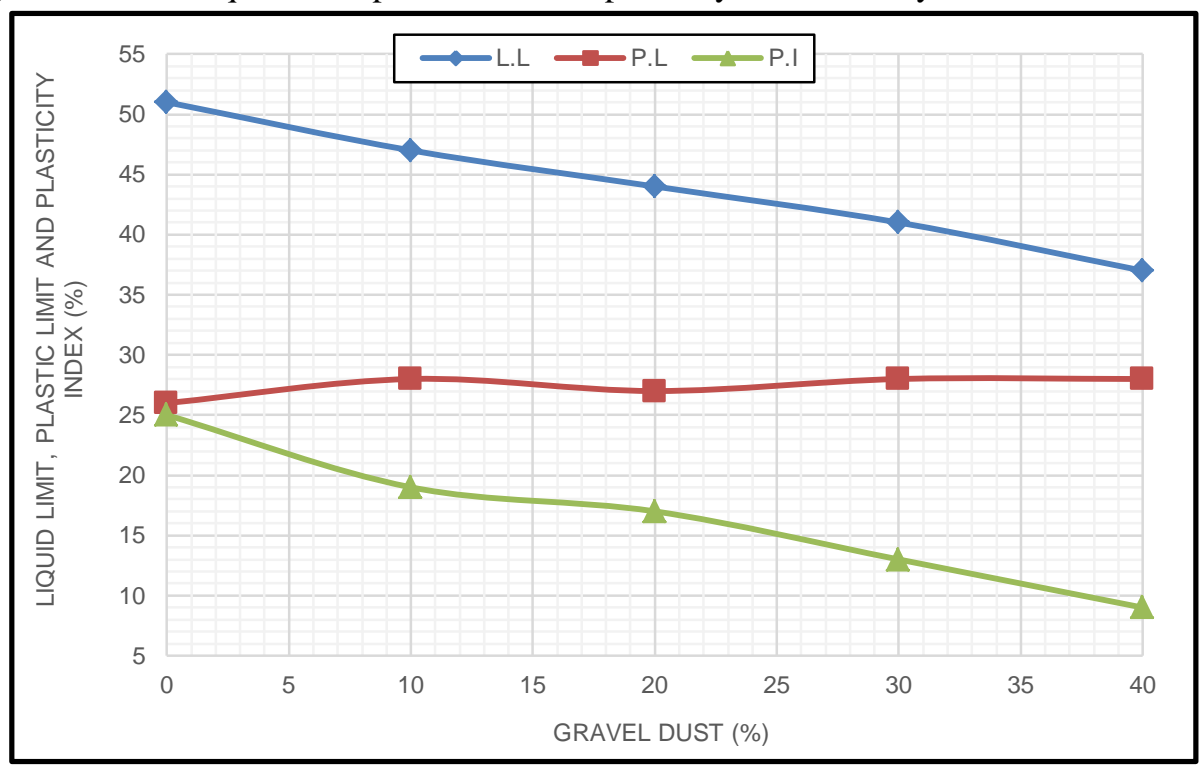

Fig. (3): Variation of liquid limit, plastic limit and plasticity index for clay as gravel dust increases

\subsection{Shrinkage Limit}

Figure 4 shows the results of the shrinkage limit test for soil mixture with limestone dust and gravel dust. The shrinkage limit (SL) of virgin soil is $16 \%$. In general, after the addition of limestone dust and gravel dust with $(10 \%$, $20 \%, 30$ and $40 \%$ ), the value of SL is gradually reduced. With the addition of limestone dust, SL is reduced by (1, 2, 5 and 6) \% respectively. While, with the addition of gravel dust, SL is decreased by (4, 6, 9, and 11) \% respectively. Similar results were found by Sabat (2012). The results indicated that gravel dust has more decrease in SL than limestone dust. This implies that the soil sample is less expansive with the addition of gravel dust to compare with soil limestone dust mixture. Therefore, this is considered to be an improvement of the engineering properties of soil. Also, the addition of gravel reduced the capacity of soil to retain

hussein.hassan@uod.ac, en.shevan@yahoo.com, sheyan.khaled@dpu.edu.krd

${ }^{2}$ Corresponding author: Directorate of Roads and Bridges in Duhok, Kurdistan Region, Iraq 
water which in turn reduced the soil shrinkability (Kashoborozi et al., 2017).

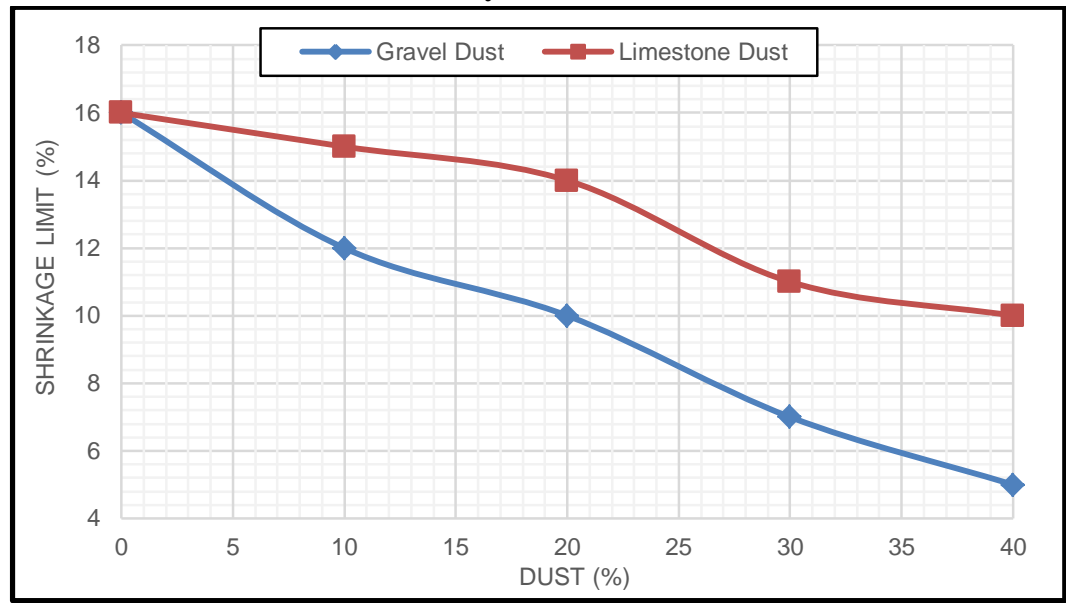

Fig. (4): Effect of limestone dust and gravel dust on shrinkage limit value of clay

\subsection{Compaction Test}

Figure 5 shows the results of compaction test for soil mixed with gravel dust and limestone dust. The MDD of native soil was $1800 \mathrm{~kg} / \mathrm{m}^{3}$ and its OMC of native soil was $15.9 \%$. The results clearly demonstrate that the MDD was higher only for native soil and it decreased as the percentage of gravel dust increased. Sharma and Hymavathi (2016) mentioned two reasons behind decrease in MDD. The first one is attributed to the low density of gravel dust which replaces soil particles as compared to clay in clay-gravel dust mixture. The second one, flocculation/aggregation of the particles occupy more spaces and change the soil gradation lead to resistance the densification of soil gravel mixture.

Conversely, MDD increased as the percentage of limestone dust increased in the composite. This result is compatible with previous results such as Agrawal and Gupta (2011), Memon et al. (2015), Ogila (2016) and Ahmed et al. (2020). The addition of limestone dust caused the soil to be coarser and result in higher MDD (Ahmed et al., 2020). Mixing limestone dust with clay is facilitating the clay compaction at low moisture content and result in densification structure with lower void ration and higher density (Ogila, 2016). The OMC of clay is $15.9 \%$ with increasing the percentage of limestone dust in the mixture the $\mathrm{OMC}$ is decreased up to $12.2 \%$ at $40 \%$ of limestone dust. This is attributed to the reduction in clay content of mixture by replacement with dust which has less attraction for water. On the other hand, OMC of mixture decreased up to $13.8 \%$ at $30 \%$ of gravel dust. Beyond the $30 \%$ of gravel dust, there was an anomalous rise in the $\mathrm{OMC}$, as shown in figure 6. This increase in OMC is due to the affinity of soil for more water in order to complete the cation exchange reaction and lubricate the particles of soil to attain effective compaction (Tugume et al., 2018; Satyanarayana et al., 2018; Sharma and Hymavathi, 2016; Brooks et al., 2011). 


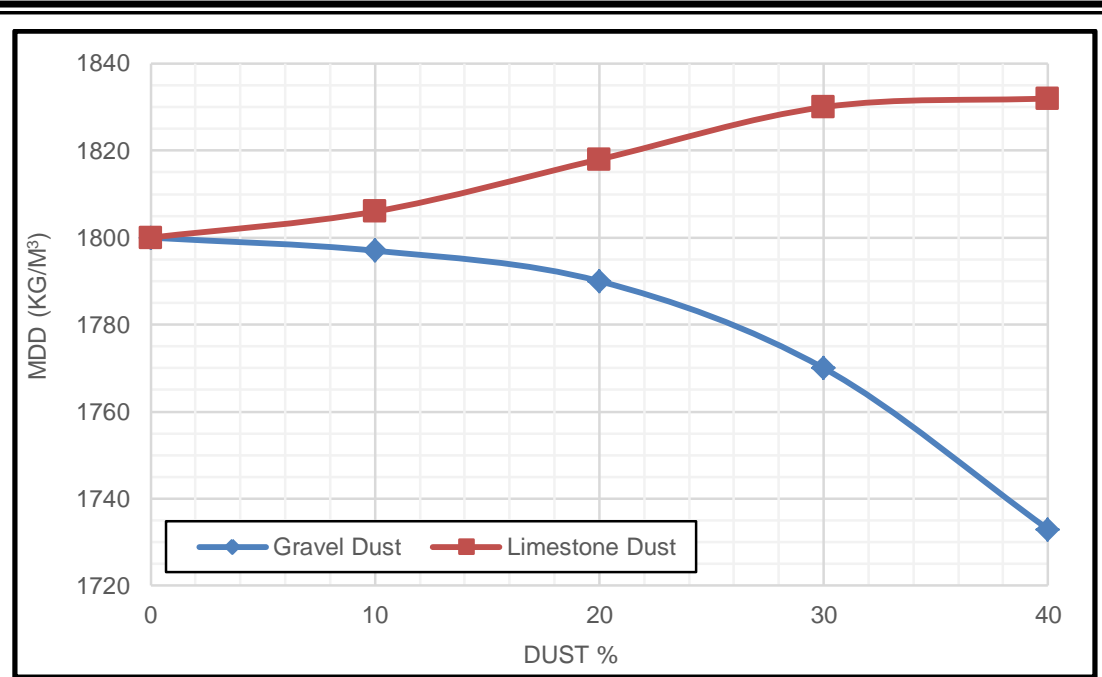

Fig. (5): Variation of MDD for clay as gravel dust and limestone dust increases

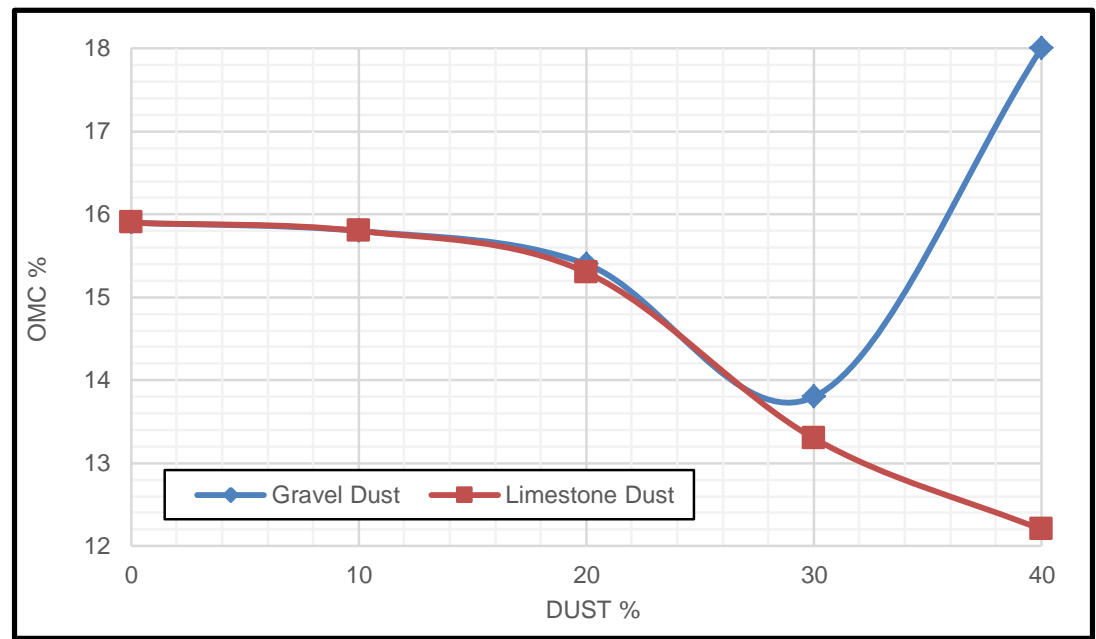

Fig. (6): Variation of OMC for clay as gravel dust and limestone dust increases

\subsection{California Bearing Ratio (CBR) Test}

The results of the CBR test for native soil and soil mixed with gravel dust and limestone dust are shown in figure 7 . The CBR value of native soil was $3.2 \%$. From the test results, it was observed that the addition of gravel dust gradually increased the CBR value of soil. The values of CBR at $(10 \%, 20 \%, 30 \%$ and $40 \%)$ of gravel dust were $(4.1 \%, 5 \%, 7.2 \%$, and $11.6 \%)$ respectively. The highest value of $\mathrm{CBR}$ was found at $40 \%$ gravel dust which increased by $8.4 \%$. Several researchers were also found similar behaviour Tugume et al. (2018), Jemal et al. (2019), Kashoborozi et al. (2017) and Chansoria and Yadav (2016). Tugume et al., (2018) reported that adding gravel dust to the soil will increase the resistant of soil to crashing when the load is gradually applied. Rana et al. (2018) found that addition of $30-40 \%$ crushed gravel dust to soil obtained highest CBR value due to effective interaction between crushed dust and soil fines and this increased the shear resistance of soil to compression.

For the soil mixed with limestone dust, a slight improvement in the CBR value of soil was observed. The values of CBR at $(10 \%, 20 \%, 30 \%$ and $40 \%)$ of limestone dust were $(3.7 \%, 4.2 \%$, $3.9 \%$, and $3.8 \%$ ) respectively. These data found that the CBR of soil is slightly increased by $1 \%$ at $20 \%$ limestone dust, further addition of limestone dust, slightly decreased this value. The results imply that limestone dust has a limited effect on enhancing the CBR value of soil. Ogundipe (2013) reported that the low

hussein.hassan@uod.ac, en.shevan@yahoo.com,_sheyan.khaled@dpu.edu.krd

${ }^{2}$ Corresponding author: Directorate of Roads and Bridges in Duhok, Kurdistan Region, Iraq 
improvement in CBR of soil could be due to the high amount of lime in clay which prevents the early strength gain due to flocculation.
From the above it can be concluded that gravel dust is more efficient than limestone dust on improvement of the CBR of soil.

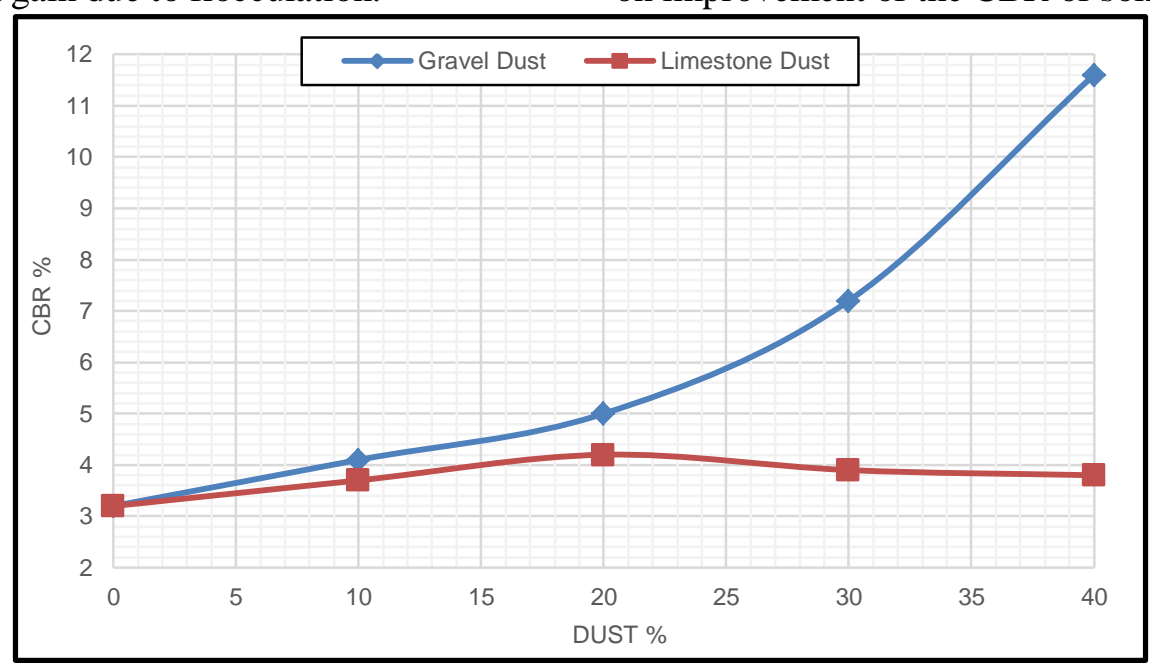

Fig. (7): Effect of limestone dust and gravel dust on CBR value of clay

\subsection{Swelling}

The results of the swelling test of native soil and soil mixed with gravel dust and limestone dust are depicted in the figure 8 . The value of swelling index for native soil was $8.47 \%$. The test results revealed that addition of gravel dust significantly decreased the swelling index of soil. As the amount of gravel dust increased, the swelling index was gradually decreased. The values of swelling index at $(10 \%, 20 \%, 30$ and $40 \%)$ of gravel dust were $(7.47 \%, 6.71 \%, 4.67 \%$, and $2.37 \%$ ) respectively. The highest decrease in swelling index was attained at $40 \%$ gravel dust by $6.1 \%$. Malik and Priyadarshee (2018) stated that a decrease in the swell index is attributed to the replacement of soil particles with non-plastic fines of gravel dust.

Regarding the effect of limestone dust on swelling behaviour of soil, it can be observed from figure 8 that swelling index was also gradually decreased after the addition of limestone dust. The values of swelling index at $(10 \%, 20 \%, 30$ and $40 \%)$ of limestone dust were (7.95\%, 7.5\%, 7.05, and 5.66\%) respectively. These results are similar to other researchers that also found similar results Ahmed et al. (2020), Pastor et al. (2019) and Ogila (2016). Brooks et al. (2011) reported that cation exchange is responsible for the reduction in swelling behaviour of soil when mixed with limestone powder, which causes the sodium ions to be replaced by calcium ions. The test results imply that limestone dust has a limit impact on enhancing the swelling behaviour of soil if it compared with gravel dust. 


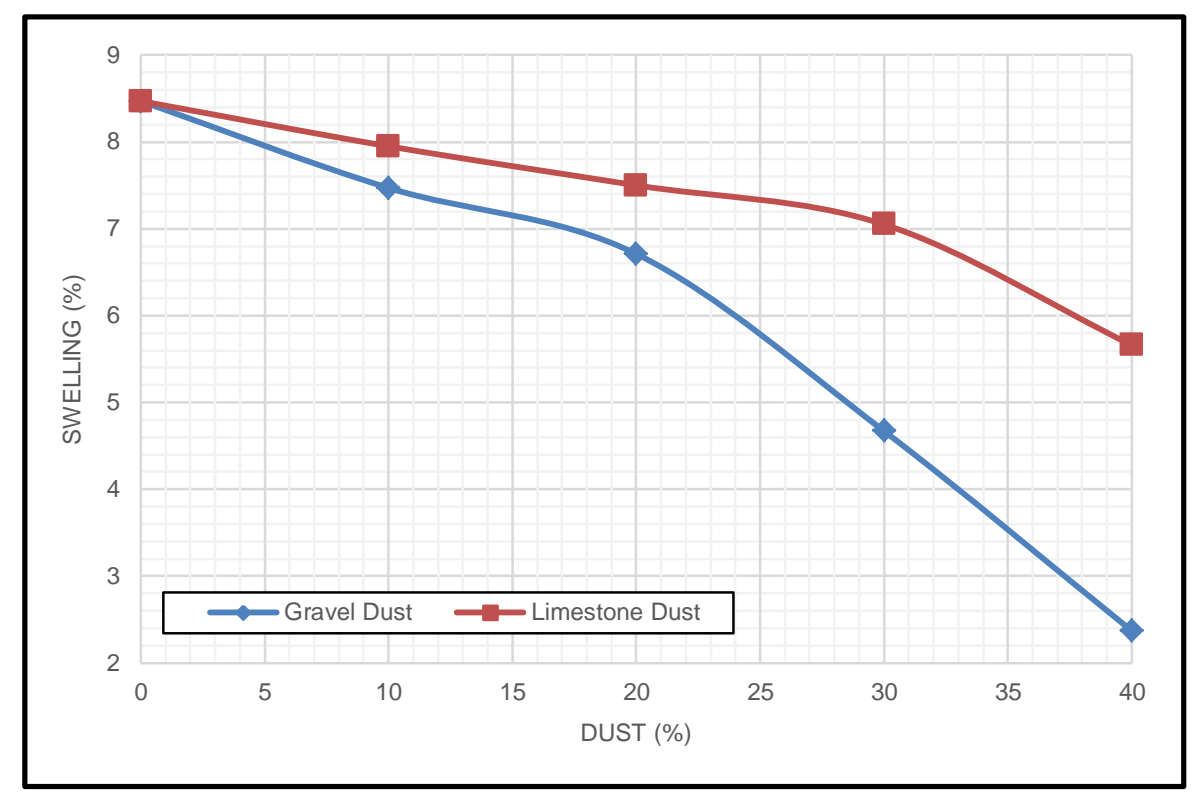

Fig. (8): Effect of limestone dust and gravel dust on swelling value of clay

\section{CONCLUSIONS}

In this study, the effects of gravel dust and limestone dust on the geotechnical characteristics of clay were investigated, the following conclusions were drawn:

- Atterberg limits mostly decreased with addition gravel dust and limestone dust in clay; with the addition of dust, the clay particles decreased.

- The MDD decreased with an increase in the amount of gravel dust in clay. This is due to the lower density of the gravel dust.

- Gravel dust mixed with clay showed decreased in OMC value by adding up to $30 \%$ and then beyond there was an anomalous rise in the OMC with additional increment in gravel dust content.

- The OMC decreased and the MDD increased gradually as the amount of limestone dust increased.

- Limestone dust mixed with clay showed slightly enhancement in CBR value with adding up to $20 \%$ and there beyond decreased with additional increment in limestone dust content in soaked condition.

- Soaked CBR value increased gradually with an increase in the percentage of the gravel dust content to the clay.

- A significant decrease in the swelling percentage value of the clay is found after the addition of dust. The gravel dust has the highest reduction in swelling percentage compared to limestone dust.

- It is observed from the study that the performance of gravel dust is much more effective when compared to limestone dust.

- The use of limestone dust and gravel dust can be effective in geotechnical applications as stabilization materials.

\section{ACKNOWLEDGEMENTS}

This research was supported by the field laboratories at HGG Company, that provided all required materials and equipment utilized for the testing program. The authors would like to thank the Directorate of roads and bridges in Duhok, the technical staff of the Duhok Construction Laboratory and HGG Company.

hussein.hassan@uod.ac, en.shevan@yahoo.com,_sheyan.khaled@dpu.edu.krd

${ }^{2}$ Corresponding author: Directorate of Roads and Bridges in Duhok, Kurdistan Region, Iraq 


\section{REFERENCES}

Agrawal, V., and Gupta, M. (2011). Expansive soil stabilization using marble dust. International Journal of Earth Sciences and Engineering, 4(6), pp.59-62.

Ahmed, A. H., Hassan, A. M., and Lotfi, H. A. (2020). Stabilization of Expansive Sub-grade Soil Using Hydrated Lime and Dolomitic-Limestone By-Product (DLP). Geotechnical and Geological Engineering, 38(2), pp.1605-1617.

Brooks, R., Udoeyo, F. F., and Takkalapelli, K. V. (2011). Geotechnical properties of problem soils stabilized with fly ash and limestone dust in Philadelphia. Journal of Materials in Civil Engineering, 23(5), pp.711-716.

Bshara, A. S., Bind, E. Y., and Sinha, P. K. (2014). Effect of stone dust on geotechnical properties of poor soil. International Journal of Civil Engineering \& Technology (IJCIET), 5(4), pp.37-47.

Chansoria, A. and Yadav, R. K. (2016). Effect of quarry dust on engineering properties of black cotton soil. Int. J. Innov. Res. Sci. Technol, 2(11), pp.715-718.

Dixit, D. M., and Patil, D. K. (2016). Utilization of Stone Dust to Improve the Properties of Expansive Soil. International Journal of Civil Engineering and Technology (IJCIET), 7(4), pp.440-447.

Jemal, A., Agon, E. C., and Geremew, A. (2019). UTILIZATION OF CRUSHED STONE DUST AS A STABILIZER FOR SUB GRADE SOIL: A CASE STUDY IN JIMMA TOWN. Annals of the Faculty of Engineering Hunedoara, 17(4), pp.55-64.

Kashoborozi, O., Aturinda, E., Jjuuko, S., and Kalumba, D. (2017). Use of Crushed Concrete Aggregate Waste in Stabilization of Clayey Soils for Sub Base Pavement Construction. 9th South African Young Geotechnical Engineers Conference, 13, 14 \& 15 September 2017.

Malik, V., and Priyadarshee, A. (2018). Compaction and swelling behavior of black cotton soil mixed with different non-cementitious materials. International Journal of Geotechnical Engineering, 12(4), pp.413-419.

Memon, N. A., Abro, F., Bhutto, M. A., and Sumadi, S. R. (2015). Marble powder as stabilizer in natural clayey soils. J Sci Int (Lahore), 27(4), pp.4105-4110.

Negi, A. S., Faizan, M., Siddharth, D. P., and Singh, R. (2013). Soil stabilization using lime. International journal of innovative research in science, engineering and technology, 2(3), pp.448-453.

Ogila, W. A. M. (2016). The impact of natural ornamental limestone dust on swelling characteristics of high expansive soils. Environmental Earth Sciences, 75(24), p.1493.

Ogundipe, O. M. (2013). An investigation into the use of lime-stabilized clay as subgrade material. International Journal of Scientific and Technology Research, 2(10), pp.82-86.

Okagbue, C. O. (2007). Stabilization of clay using woodash. Journal of materials in civil engineering, 19(1), pp.14-18.

Pastor, J. L., Tomás, R., Cano, M., Riquelme, A., and Gutiérrez, E. (2019). Evaluation of the Improvement Effect of Limestone Powder Waste in the Stabilization of Swelling Clayey Soil. Sustainability, 11(3), p.679.

Pete Lien and Sons (2015). What is the difference between lime and limestone?. [Online] Available:

https://www.petelien.com/22-lime-faqs/54-wh at-is-the-difference-between-lime-and-limesto ne (August 3, 2020).

Rana,S.; Naidu, C. and Kumar, M. (2018) Stabilization of Sub Base Soil using Crusher Dust. International Journal of Engineering Science and Computing. Volume 8 Issue No.5.

Sabat, A. K. (2012). A study on some geotechnical properties of lime stabilized expansive soil-quarry dust mixes. International Journal of emerging trends in engineering and hussein.hassan@uod.ac, en.shevan@yahoo.com,_sheyan.khaled@dpu.edu.krd

${ }^{2}$ Corresponding author: Directorate of Roads and Bridges in Duhok, Kurdistan Region, Iraq 
development, 1(2), pp.42-49.

Sabat, A. K., and Muni, P. K. (2015). Effects of limestone dust on geotechnical properties of an expansive soil. Int. J. Appl. Eng. Res, 10, 37724-37730.

Satyanarayana, P. V. V., Raghu, P., Kumar, R. A., and Pradeep, N. (2013). Performance of crusher dust in high plastic gravel soils as road construction material. IOSR Journal of mechanical and civil engineering, 10(3), pp.1-5.

Satyanarayana, P; Parimi, S.; Swathipriya, and Jahara, S. (2018). A Study on Suitability of Crusher Dust Stabilized Red Earth and Gravel as Subgrade and Sub Base Material. SSRG International Journal of Civil Engineering, 5(4), pp.9-15.

Sharma, R. K., and Hymavathi, J. (2016). Effect of fly ash, construction demolition waste and lime on geotechnical characteristics of a clayey soil: a comparative study. Environmental Earth Sciences, 75(5), p.377.
Sivrikaya, O., Kıyıldı, K. R., and Karaca, Z. (2014). Recycling waste from natural stone processing plants to stabilise clayey soil. Environmental Earth Sciences, 71(10), pp.4397-4407.

Thompson, M. R. (1967). Factors influencing the plasticity and strength of lime-soil mixtures. University of Illinois at Urbana Champaign, College of Engineering. Engineering Experiment Station.

Tiwari, D.K., Dixit, R.K. and Roy, S. (2016). Study on Stabilization of Black Cotton Soil by Using Stone Dust \& Polypropylene Fibers. International Journal of Innovative Research in Science, Engineering and Technology. Vol. 5 , Issue 9.

Tugume, B., Owani, I., Jjuuko, S., and Kalumba, D. (2018). Performance of Lateritic Soils Stabilized with Both Crushed Rock Aggregates and Carbon Black as a Pavement Base Layer. In The International Congress on Environmental Geotechnics (pp. 382-388). Springer, Singapore. hussein.hassan@uod.ac, en.shevan@yahoo.com,_sheyan.khaled@dpu.edu.krd

${ }^{2}$ Corresponding author: Directorate of Roads and Bridges in Duhok, Kurdistan Region, Iraq 